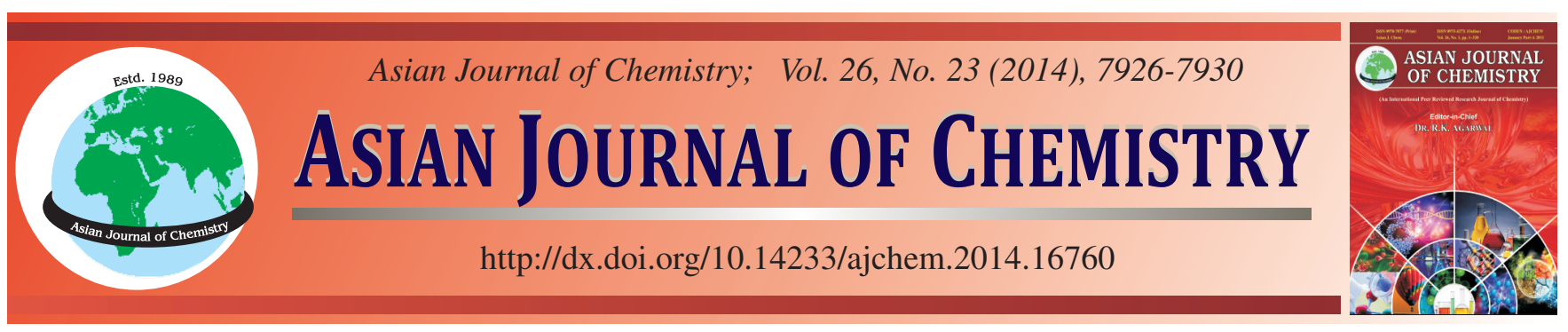

\title{
Study on Interaction Between Perylene Derivative and Bovine Serum Albumin
}

\author{
Yong-Shan MA*, Ning Wang, Jun-Sen Wu, Hui-Xue Ren, Lei Liu and Qi Wang
}

School of Municipal and Environmental Engineering, Shandong Jianzhu University, Jinan 250101, Shandong Province, P.R. China

*Corresponding author: Tel/Fax: +86 531 86361570; E-mail: mlosh@sdjzu.edu.cn

Received: 26 November 2013;

Accepted: 13 March 2014;

Published online: 15 November 2014;

AJC-16265

\begin{abstract}
$N, N^{\prime}$-bis(L-glutamic amine)-perylene-3,4,9,10-dicarboxylic diimide (PTCDG) was synthesized and characterized, which is water-soluble and yielded high fluorescent quantum. The interaction between PTCDG and bovine serum albumin (BSA) was investigated with fluorescence and absorbance spectroscopy techniques, as well as the influence of the ion intensity on the interaction. The results showed that infinitesimal bovine serum albumin could decrease the fluorescence intensity of PTCDG and the quenching efficiency was altered with change of bovine serum albumin surface charge. Meanwhile, the fluorescence of bovine serum albumin was quenched by PTCDG and the fluorescence intensity of PTCDG increased. The spectra displayed isoacitinic emission point at $515 \mathrm{~nm}$, demonstrating the existence of the interaction and energy transfer between PTCDG and bovine serum albumin.
\end{abstract}

Keywords: Perylene derivative, Bovine serum albumin, Absorption spectrum, Flourescence spectrum.

\section{INTRODUCTION}

Perylene derivatives are organic dyes, which have various applications, such as solar cells, optical switches, chemical sensors, field-effect transistors, light-emitting diodes, colorful liquid crystal displays and electrophotographic photoreceptors ${ }^{1-3}$. Owing to high molar absorptivity, they qualified with high quantum yields of fluorescence, excellent thermal and photochemical stabilities and electrochemical performance ${ }^{4-5}$. Perylene-3,4,9,10-tetracarboxylate derivatives had been widely studied for biochemical and pharmacological purposes because they could work as G-quadruplex telomere targeting agents, potential anticancer agents, telomerase inhibitors and antibacterial agents ${ }^{6-8}$. However, perylene moiety is a kind of heavier polyaromatic hydrocarbon, tending to have carcinogenic, chronic impact potential and phototoxic effect ${ }^{9}$.

Serum albumins (SA), the most abundant soluble protein in the systemic circulation comprising 52-60\% in plasma, could serve as a transport carrier of drugs. It played a dominant role in drug disposition and efficacy for increasing the apparent solubility of hydrophobic drugs in plasma ${ }^{10}$. Their conformation changes that altered their secondary and tertiary structure of albumin were affected by the binding of a ligand to serum albumins ${ }^{11}$. Studies on the interaction of ligands with serum albumins were significant ${ }^{12}$, furnishing information on the structural features, which determined the therapeutic effectiveness of drugs. These binding studies were becoming a vital and fascinating research field in chemistry, clinical medicine and life sciences ${ }^{13}$. Bovine serum albumin had been one of the most extensively studied of this group of proteins, particularly because of its structural homology with human serum albumin $(\mathrm{HSA})^{14}$. Many researchers focused on the binding interaction between serum albumins and various organic molecules. But the interaction of $N, N^{\prime}$-bis(L-glutamic amine)perylene-3,4,9,10dicarboxylic diimide (PTCDG) with serum albumins had not been reported so far. This paper investigated the association of PTCDG with bovine serum albumin.

In the investigation of interactions between the drug molecule and serum albumins at low concentration under physiological condition, fluorescence spectroscopy played a crucial role $^{15}$. Sufficient information about the structural fluctuations and the microenvironment changes surrounding the fluorophore in the protein could be acquired from the measurements and analyses of the fluorescence emission spectra ${ }^{16}$. In this research, the binding interaction of PTCDG with bovine serum albumin was investigated, using the fluorescence spectroscopic and absorbance spectroscopy techniques. The interactions between PTCDG and bovine serum albumin were investigated, as well as the influence of the ion intensity on the interaction between them.

\section{EXPERIMENTAL}

Perylene-3,4,9,10-tetracarboxylic acid dianhydride, L-glutamic amine, dimethyl sulfoxide, ethanol, hydrochloric acid, ammonia and bovine serum albumin powder were of reagent grade, purchased from Merk, ACROS and Sigma- 
Aldrich. and distilled freshly according to standard procedure. Column chromatography was performed using silica gel (4060 mesh). bovine serum albumin solutions were prepared with $\mathrm{pH} 7.4$ phosphate buffer solution and stored at $0-4{ }^{\circ} \mathrm{C}$. All the experiments were performed at $25^{\circ} \mathrm{C}$.

INOVA 400-MHz spectrometer (BRUKER, Germany) was used to recorded ${ }^{1} \mathrm{H}$ NMR spectra at room temperature with tetramethyl silane (TMS) in deuterium generation of water $\left(\mathrm{D}_{2} \mathrm{O}\right)$ as internal standard. Infrared spectra of samples mixed with $\mathrm{KBr}$ pellets were obtained through TENSOR-27 Fourier transform FT-IR spectrophotometer (BRUKER Germany). Mass spectra were recorded with a Finnigan ESI instrument (THERMO America), in which data were presented in $\mathrm{m} / \mathrm{z}(\%)$ values. UV-visible absorption spectra were recorded with a CARY50 UV-visible spectrophotometer (VARIAN, America). Fluorescence measurements were performed on an FL-4500 PC spectrofluorophotometer (HITACHI, Japan). All samples were degassed for $15 \mathrm{~min}$ with pure nitrogen gas before tests.

Synthesis of $N, N^{\prime}$-bis(L-glutamic amine)perylene-3,4,9,10dicarboxylic diimide (PTCDG): The reaction routes for PTCDG synthesis could be found in Fig. 1. The preparation of intermediate (compound 2) followed the procedure presented in previous literature ${ }^{17,18}$ : The mixture of perylene-3,4,9,10tetracarboxylic acid dianhydride $(0.8 \mathrm{~g}, 2 \mathrm{mM})$ and L-glutamic amine ( $5 \mathrm{~g}, 30 \mathrm{mM}$ ) was dissolved in $80 \mathrm{~mL}$ of dimethyl sulfoxide and heated at reflux for $6 \mathrm{~h}$. After being cooled to room temperature and centrifuged, the precipitate was washed with $60 \mathrm{~mL}$ of ethanol $(3 \times 20 \mathrm{~mL})$ and then dissolved in $80 \mathrm{~mL}$ of water. When the solution $\mathrm{pH}$ was adjusted to 1 with diluted hydrochloric acid, the precipitate was separated out. Then, the compound $\mathbf{2}$ was obtained by being filtered and washed with $60 \mathrm{~mL}$ of water $(3 \times 20 \mathrm{~mL})$. The intermediate product was allowed to react with $20 \mathrm{~mL}$ of $15 \% \mathrm{NH}_{3} \cdot \mathrm{H}_{2} \mathrm{O}$ and stirred at room temperature for $10 \mathrm{~min}$. The precipitate was filtered off as solvent being evaporated. $N, N^{\prime}$-bis(L-glutamic amine)perylene-3,4,9,10-dicarboxylic diimide model compound was obtained as a brown powder $(0.9 \mathrm{~g}, 73 \%$ yield $)$ with being dried at $100{ }^{\circ} \mathrm{C}$ under vacuum. ${ }^{1} \mathrm{H}$ NMR $\left(\mathrm{D}_{2} \mathrm{O}\right.$, TMS, ppm): $\delta_{\mathrm{H}} 8.57(\mathrm{~d}, 4 \mathrm{H}), 7.92(\mathrm{~d}, 4 \mathrm{H}), 5.12(\mathrm{~m}, 2 \mathrm{H}), 2.53$ $(\mathrm{m}, 4 \mathrm{H}), 2.36(\mathrm{~m}, 4 \mathrm{H})$. FT-IR $\left(\mathrm{KBr}, \mathrm{v}_{\max }, \mathrm{cm}^{-1}\right)$ : v 3433, 3164, 3052, 2847, 1689, 1592, 1361, 1345, 1273, 1182, 1114, 1021, 951, 853, 809, 793, 737, 659, 461, 432. MS (EI): (m/z): 646.2 $[\mathrm{M}+1]^{+}$.

Analytical method: The interaction between PTCDG and bovine serum albumin was monitored, the concentration of PTCDG was kept constant at $2.5 \mathrm{mM}$ and the concentration of bovine serum albumin has been varied from 0 to $2.5 \mathrm{mM}$. This mixture was sonicated in an ultrasonic bath for $1 \mathrm{~min}$.

\section{RESULTS AND DISCUSSION}

Photophysical properties of $N, N^{\prime}$-bis(L-glutamic amine)perylene-3,4;9,10-dicarboxylic diimide: The electronic absorption of perylene diimide, has a pronounced coupling to the vibronic features corresponding to quantum vibrational numbers transitions $\left(v=0 \rightarrow v^{\prime}=0,1\right.$ and 2 , where, $v$ and $v^{\prime}$ are the ground and excited states, respectively $\left.{ }^{19,20}\right)$. The similar propertie could also be found in Fig. 2, presenting the absorption and fluorescence spectrum of aqueous PTCDG. In the absorption spectrum, a shoulder and two absorbance peaks centered at 467, 497 and $533 \mathrm{~nm}$ could attribut to the electronic transitions of $v=0 \rightarrow v^{\prime}=2,1$ and 0 , respectively. Two maximum emissions were observed at $554 \mathrm{~nm}(0 \rightarrow 0$ transition $)$ and $586 \mathrm{~nm}(0 \rightarrow 1$ transition $)$ in the fluorescence spectrum of PTCDG excited at $533 \mathrm{~nm}$ and the maximum emission at $554 \mathrm{~nm}(0 \rightarrow 0$ transition $)$ was a mirror image relative to the 0 $\rightarrow 0$ absorption with a stokes-shift of $21 \mathrm{~nm}$.

Photophysical characteristics of PTCDG with bovine serum albumin: The spectra of absorption and fluorescence of perylene derivatives are used as tools to monitor the interaction with other molecular compunds, such as proteins, owing to the sensitive responses of the intensity and location of absorption maximum and fluorescence maximum corresponding to the medium.

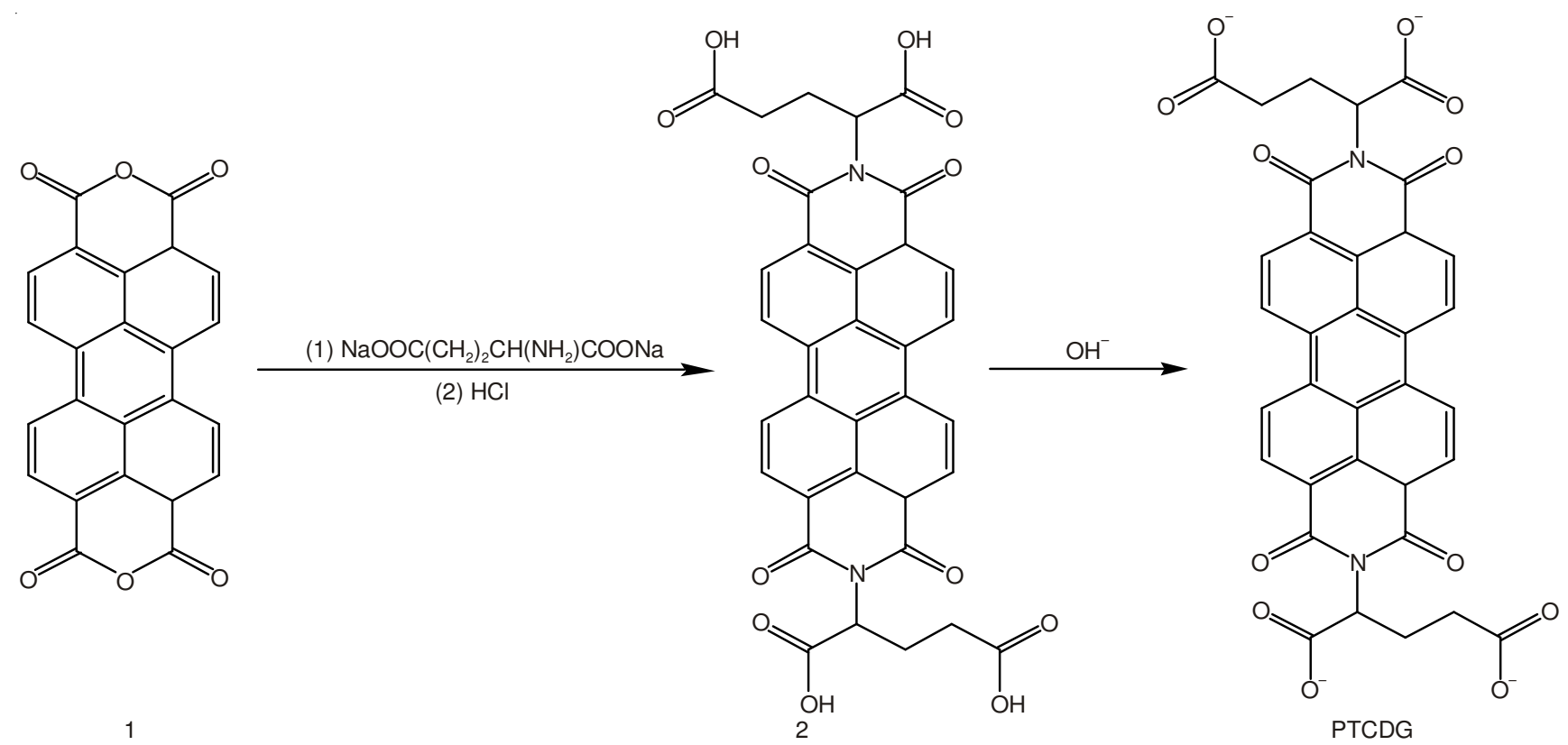

Fig. 1. Synthesis route of $N, N^{\prime}$-bis(L-glutamic amine)perylene-3,4,9,10-dicarboxylic diimide (PTCDG) 


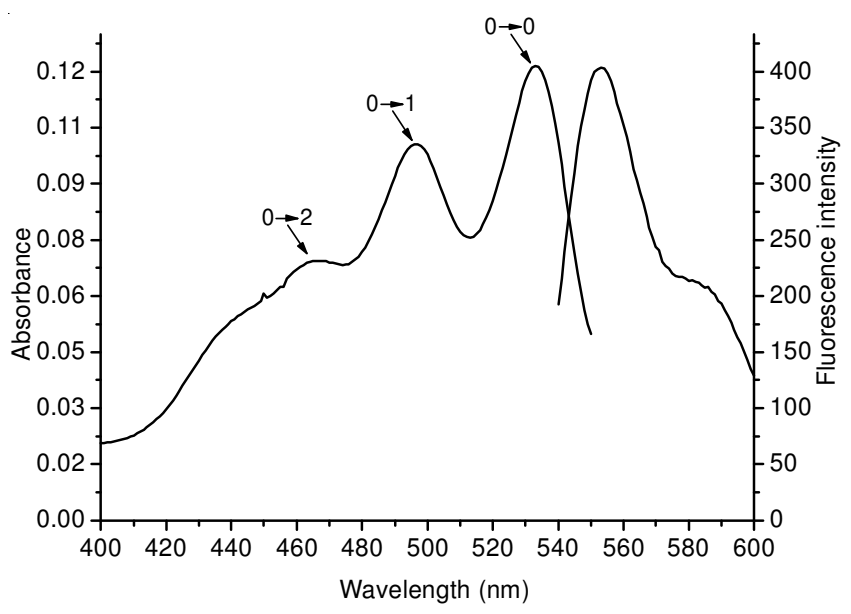

Fig. 2. Absorption and fluorescence spectrum of $N, N^{\prime}-b i s$ (L-glutamic amine)perylene-3,4,9,10-dicarboxylic diimide
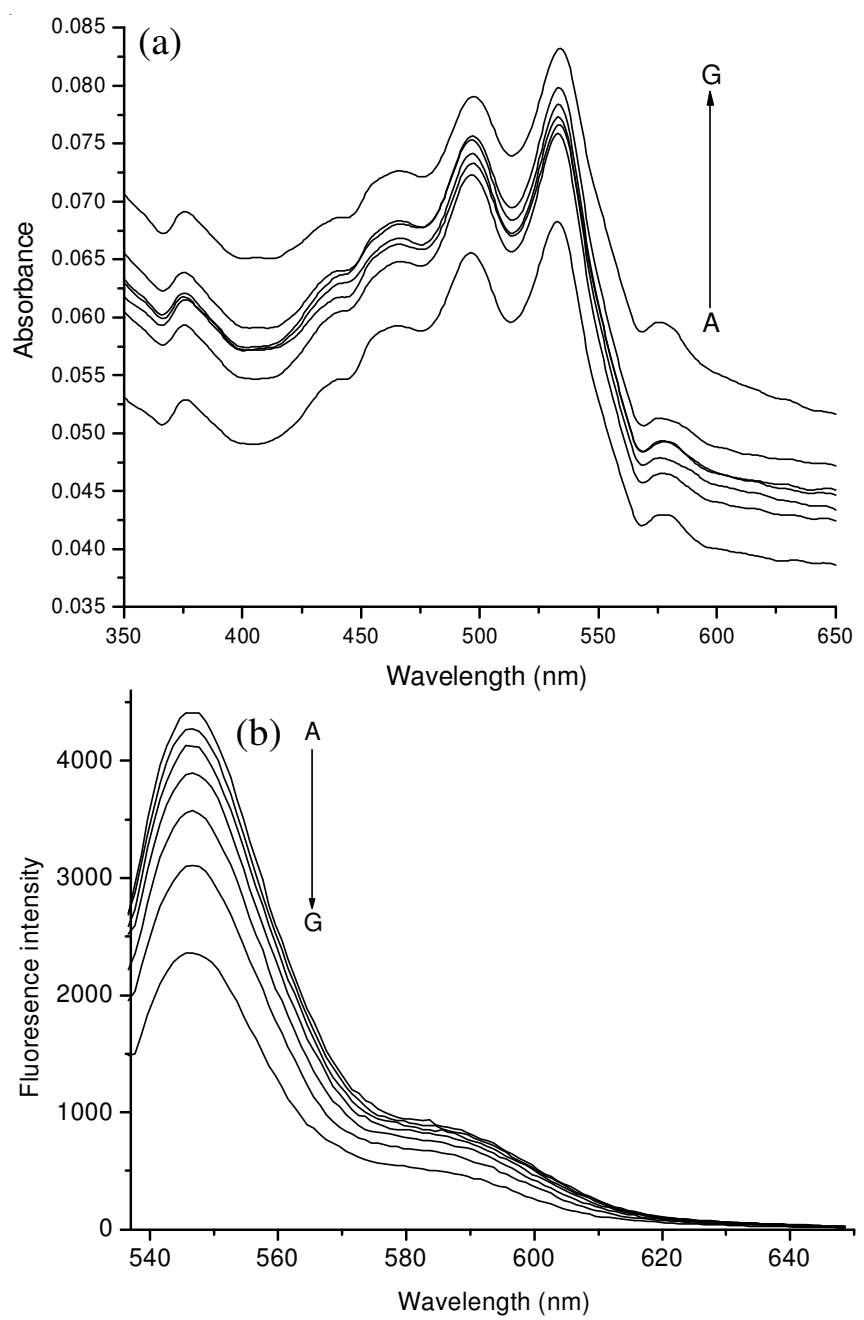

Fig. 3. Absorption (a) and fluorescence (b) spectrum $\left(\lambda_{\text {ex }}=533 \mathrm{~nm}, \mathrm{~T}=298\right.$ $\mathrm{K})$ of $N, N^{\prime}$-bis (L-glutamic amine)perylene-3,4,9,10-dicarboxylic diimide $\left(5 \times 10^{-6} \mathrm{~mol} / \mathrm{L}\right)$ at different concentrations of bovine serum albumin. Curve A-G: $\mathrm{c}(\mathrm{BSA})=(0.0,0.5,1.17,2.5,5.2,12,25) \times$ $10^{-7} \mathrm{~mol} / \mathrm{L}$

Fig. 3 shows the spectra of UV-visible absorption and steady-state fluorescence of PTCDG samples with bovine serum albumin. It was found that PTCDG in water exhibited intense absorption in the wavelength range from 400 to 600 $\mathrm{nm}$ with maximum absorption at $533 \mathrm{~nm}$. Even with bovine serum albumin increasing, the spectra of both absorption and fluorescence were almost identical to those of BSA-free PTCDG, but the intensity showed striking change. This could be explained by the fact that bovine serum albumin improved the absorption intensities of PTCDG compared to those in water, while decreased the fluorescence intensities remarkably without alteration in the shape of the spectrum.

The fluorescence quenching is usually analyzed by the well known Stern-Volmer equation ${ }^{21,22}$, as follows in eqn. 1:

$$
\mathrm{I}_{0} / \mathrm{I}_{\mathrm{f}}=1+\mathrm{K}_{\mathrm{sv}}[\mathrm{Q}]
$$

where $I_{0}$ and $I_{f}$ denote the steady state fluorescence intensities in the absence and presence of the quencher Q, respectively; [Q] is the quencher concentration; $\mathrm{K}_{\mathrm{sv}}$ is the Stern-Volmer quenching constant.

The Stern-Volmer plot of bovine serum albumin is shown in Fig. 4a $([\mathrm{NaCl}]=0)$. Based on the slope, the Stern-Volmer quenching constant $\left(\mathrm{K}_{\mathrm{sv}}\right)$ is $3.97 \times 10^{6} \mathrm{~L} / \mathrm{mol}$. The influences of formation of BSA/ $\mathrm{Na}^{+}$complexes were also been investigated, as shown in the Fig. 4b, depicting the Stern-Volmer plots of fluorescence quenching of PTCDG by BSA/ $\mathrm{Na}^{+}$ complexes. The addition of $\mathrm{NaCl}$ solution decreased the fluorescence quenching rate of PTCDG by bovine serum albumin. This resulted from the formation of $\mathrm{BSA} / \mathrm{Na}^{+}$complexes, owning to the electrostatic interaction between anionic patches on bovine serum albumin and cationic $\left(\mathrm{Na}^{+}\right)$on $\mathrm{NaCl}$ at $\mathrm{pH} 7$. The complex could induce and stabilize the folded structure of bovine serum albumin, offering PTCDG with a hydrophobic microenvironment, which in turn increased the fluorescence intensities of it.

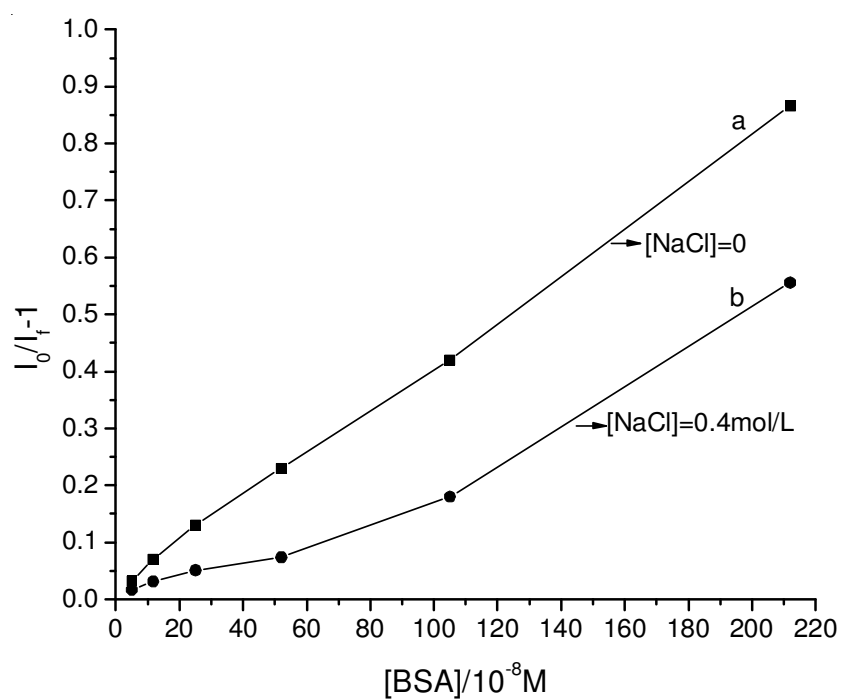

Fig. 4. Stern-Volmer plots of fluorescence quenching of $N, N^{\prime}-b i s(\mathrm{~L}-$ glutamic amine)perylene-3,4,9,10-dicarboxylic diimide by bovine serum albumin

Photophysical characteristics of bovine serum albumin with PTCDG: The UV-visible spectra of bovine serum albumin $(5 \mathrm{mmol} / \mathrm{L})$ in the absence and presence of PTCDG $(0-5 \mathrm{mmol} / \mathrm{L})$ were indicated in Fig. 5a. The peak at $278.5 \mathrm{~nm}$ could attribute to the $\pi-\pi^{*}$ transition of characteristic polypeptide backbone structure $^{23}$. The intensity of the peak increased with the gradual addition of PTCDG into bovine serum albumin. The spectral change could result from the disturbance of the microenvironment, 
caused by the binding of PTCDG with bovine serum albumin, around the polypeptide. The fluorescence emission spectra of bovine serum albumin quenched by PTCDG were shown in Fig. 5b, the fluorescence intensities of bovine serum albumin decreased remarkably with the increasing of PTCDG, but no alteration was found in the shape of the emission spectrum. This indicated that there was interaction between PTCDG and bovine serum albumin. Furthermore, increasing PTCDG caused an accompanying enhancement around the emission wavelength at 547 and $557 \mathrm{~nm}$, suggesting that there was a strong association and non-radioactive energy transfer between PTCDG and bovine serum albumin. The isoacitinic point was found at $515 \mathrm{~nm}$, presenting that the quenching of bovine serum albumin depended on the formation of PTCDG and bovine serum albumin complex.
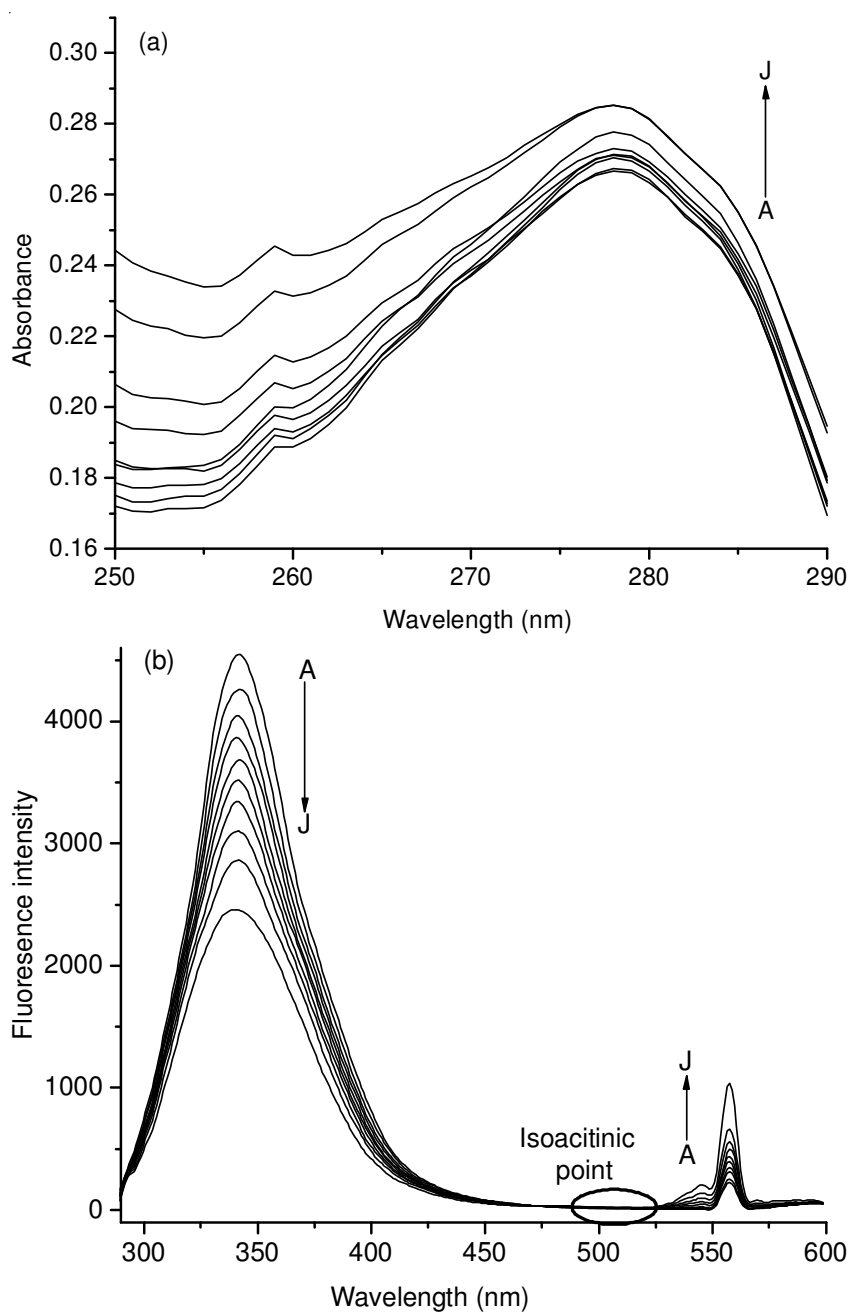

Fig. 5. Absorption (a) and fluorescence (b) spectra $\left(\lambda_{\text {ex }}=280 \mathrm{~nm}, \mathrm{~T}=298\right.$ $\mathrm{K})$ of bovine serum albumin $\left(5 \times 10^{-6} \mathrm{~mol} / \mathrm{L}\right)$ quenched by $N, N^{\prime}-$ bis(L-glutamic amine)perylene-3,4,9,10-dicarboxylic diimide. Curve A-J: $\mathrm{c}(\mathrm{PTCDG})=(0.0,0.25,1.25,2.92,6.25,12.9,21,26$, $38,44,50) \times 10^{-7} \mathrm{~mol} / \mathrm{L}$

Stern-Volmer equation is show in eqn. $2^{21,22}$ :

$$
\frac{\mathrm{F}_{0}}{\mathrm{~F}}=1+\mathrm{K}_{\mathrm{q}} \tau_{0}[\mathrm{Q}]=1+\mathrm{K}_{\mathrm{sv}}[\mathrm{Q}]
$$

where $\mathrm{F}_{0}$ and $\mathrm{F}$ denote the steady state fluorescence intensities in the absence and presence of the quencher Q, respectively;
$\mathrm{K}_{\mathrm{q}}$ is the quenching rate constant of biomolecule; $\tau_{0}$ is the average lifetime of molecule without quencher. (The value for bovine serum albumin is $10^{-8} \mathrm{~s}$ ); [Q] is the quencher concentration; $\mathrm{K}_{\mathrm{sv}}$ is the Stern-Volmer quenching constant.

Stern-Volmer plots of bovine serum albumin are shown in Fig. 6a. Based on the slope, the Stern-Volmer quenching constants $\left(\mathrm{K}_{\mathrm{sv}}\right)$ could be calculated as $1.7 \times 10^{8} \mathrm{~L} \mathrm{~mol}^{-1}$ for bovine serum albumin. The bimolecular quenching rate constant, $\mathrm{K}_{\mathrm{q}}$, of bovine serum albumin was found to be $1.7 \times 10^{16} \mathrm{~L} \mathrm{~mol}^{-1}$ $\mathrm{s}^{-1}$, which was greater than that of scatter procedure $\left(2 \times 10^{10}\right.$ $\left.\mathrm{L} \mathrm{mol}^{-1} \mathrm{~s}^{-1}\right)$. This showed that the quenching mentioned above was not initiated by dynamic collision but by the ground state complex formation of static quenching.

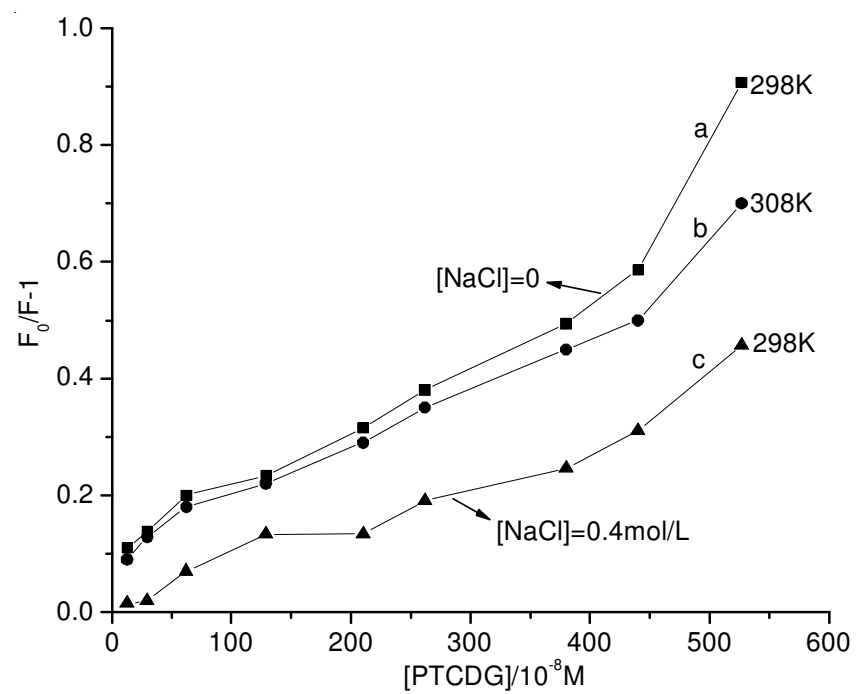

Fig. 6. Stern-Volmer plots of fluorescence quenching of bovine serum albumin by $N, N^{\prime}$-bis(L-glutamic amine)perylene-3,4,9,10dicarboxylic diimide

Fig. 6 (curve a and b) presents the Stern-Volmer curves of PTCDG-BSA system at different temperatures. It was observed that quenching constants decreased as the increasing temperature for $10^{\circ} \mathrm{C}$, which matched the fact that the fluorescence quenching of bovine serum albumin induced by the PTCDG is attributed to static quenching ${ }^{24}$.

Curve $\mathrm{c}$ in Fig. 6 shows that the fluorescence of PTCDGBSA system corresponded on ionic strength. Curves a and c implied that the fluorescence quenching rate of bovine serum albumin by PTCDG decreased as $\mathrm{NaCl}$ concentration increasing. This indicated that the interactions between the PTCDG moieties and bovine serum albumin were weakened by salt effect and the binding was dominated by electrostatic interactions.

\section{Conclusion}

In this study, a new perylene derivative was synthesized successfully, $N, N^{\prime}$-bis(L-glutamic amine)-perylene-3,4;9,10dicarboxylic diimide. The binding interaction of PTCDG and bovine serum albumin were investigated by fluorescence and absorbance spectroscopy techniques, as well as the influence of the ion intensity on the interaction. The results showed that the addition of infinitesimal bovine serum albumin could decrease the fluorescence intensity of PTCDG. The observation that PTCDG caused an accompanying enhancement around 
the emission wavelength at 547 and $557 \mathrm{~nm}$ suggests that there could be a strong association and non-radioactive energy transfer between PTCDG and bovine serum albumin. The Stern-Volmer quenching constant implied that PTCDG quenched the intrinsic fluorescence of bovine serum albumin. The interactions between the PTCDG moieties and bovine serum albumin were weakened by salt effect while the binding between both was governed by electrostatic interactions. All these results demonstrated that PTCDG could bind to bovine serum albumin, resulting in effective transporting in human body, which could benefit the investigations in pharmacy industries and toxicology.

\section{ACKNOWLEDGEMENTS}

This study was financially supported by National Major Projects on Control and Management of Water Body Pollution (Grant No. 2012ZX07404-003-006), Natural Science Funds of Shandong Province of China (Y2007B42), Research Funds of Shan Dong Jian Zhu University (XN110110).

\section{REFERENCES}

1. Y. Li, H. Li, Y. Li, H. Liu, S. Wang, X. He, N. Wang and D. Zhu, Org. Lett., 7, 4835 (2005).

2. S. Xiao, M.E. El-Khouly, Y. Li, Z. Gan, H. Liu, L. Jiang, Y. Araki, O. Ito and D. Zhu, J. Phys. Chem. B, 109, 3658 (2005).

3. Z.R. Grabowski, K. Rotkiewicz and W. Rettig, Chem. Rev., 103, 3899 (2003).

4. Y. Luo, Chin. J. Lumin., 28, 923(2007).
5. X. Hong, Q. Luo and C. Wang, Photogr. Sci. Photochem., 24, 167 (2006).

6. A. Alvino, M. Franceschin, C. Cefaro, S. Borioni, G. Ortaggi and A. Bianco, Tetrahedron, 63, 7858 (2007).

7. M. Franceschin, E. Pascucci, A. Alvino, D. D'Ambrosio, A. Bianco, G. Ortaggi and M. Savino, Bioorg. Med. Chem. Lett., 17, 2515 (2007).

8. F.J. Lynch and M.J. Geoghegan, Trans. Br. Mycol. Soc., 72, 31 (1979).

9. S. Naveenraj, M.R. Raj and S. Anandan, Dyes Pigments, 94, 330 (2012).

10. B. Klajnert and M. Bryszewska, Bioelectrochem., 55, 33 (2002).

11. Y.-Z. Zhang, X. Xiang, P. Mei, J. Dai, L.-L. Zhang and Y. Liu, Spectrochim. Acta A, 72, 907 (2009).

12. S. Sun, B. Zhou, H. Hou, Y. Liu and G.-Y. Xiang, Int. J. Biol. Macromol., 39, 197 (2006)

13. S.M.T. Shaikh, J. Seetharamappa, P.B. Kandagal, D.H. Manjunatha and S. Ashoka, Dyes Pigments, 74, 665 (2007).

14. P.L. Gentili, F. Ortica and G. Favaro, J. Phys. Chem. B, 112, 16793 (2008).

15. P. Qin, R. Liu, X. Pan, X. Fang and Y. Mou, J. Agric. Food Chem., 58, 5561 (2010).

16. J. Zhang, X.-J. Wang, Y.-J. Yan and W.-S. Xiang, J. Agric. Food Chem., 59, 7506 (2011).

17. C. Liu, X. Zhang and M. Wang, J. Natural Sci. Heilongjiang Univ., 24, 522 (2007).

18. S.M. Mackinnon and Z.Y. Wang, J. Polym. Sci. A Polym. Chem., 38, 3467 (2000).

19. W. Wang, J.J. Han, L.-Q. Wang, L.-S. Li, W.J. Shaw and A.D.Q. Li, Nano Lett., 3, 455 (2003).

20. Y. Ma, C.-H. Wang, Y.-J. Zhao, Y. Yu, C.-X. Han, X.-J. Qiu and Z. Shi, Supramol. Chem., 19, 141 (2007).

21. H Zhang, Chemical Reagents, 30, 85 (2008).

22. Y. Wei, J. Li, C. Dong, S. Shuang, D. Liu and C.W. Huie, Talanta, 70, 377 (2006).

23. B. Liu, Chinese J. Lumin., 32, 293 (2011).

24. D. Yuan, S. Feng and F. Cui, Chinese J. Appl. Chem., 26, 918 (2009). 